\title{
Avaliação da composição físico-química do concentrado proteico e farinhas liofilizadas obtidos a partir de resíduos do pirarucu (Arapaima gigas)
}

Evaluation of the chemical composition of protein concentrate and freeze-dried flours removed from pirarucu residues (Arapaima gigas)

\author{
M. C. Barbosa ${ }^{1,3 *}$; L. M. Guida ${ }^{2,3}$; A. C. Feitosa ${ }^{3}$; A. D. G. Zuñiga $a^{2,3}$ \\ ${ }^{l}$ Rede de Biodiversidade e Biotecnologia da Amazônia Legal (BIONORTE), Universidade Federal do Tocantins \\ Palmas, Tocantins, Brasil \\ ${ }^{2}$ Programa de Pós-Graduação em Ciência e Tecnologia de Alimentos (PPGCTA), Universidade Federal do \\ Tocantins Palmas, Tocantins, Brasil \\ ${ }^{3}$ Laboratório de Processos e Separação de Biomoléculas e Desidratação de Alimentos (LAPSDEA), Universidade \\ Federal do Tocantins Palmas, Tocantins, Brasil. \\ *maricarvalhob@gmail.com \\ (Trabalho avaliado e selecionado pela Comissão do III CTOCTA)
}

\begin{abstract}
O pirarucu (Arapaima gigas) é considerado um dos maiores peixes de água doce do mundo. Porém o seu beneficiamento gera grandes quantidades de resíduos que podem agregar valor no desenvolvimento de novos produtos, gerar renda à população local e ainda possibilidade da difusão do seu consumo. Dentre os métodos de desidratação existentes, a liofilização se destaca por promover uma maior preservação das características sensoriais e nutricionais dos alimentos. Os concentrados proteicos provenientes de pescado são produtos obtidos por desidratação que possuem alto conteúdo de proteínas. Suas características primordiais são o alto valor biológico, baixo custo e fácil conservação. O objetivo desse trabalho foi avaliar a composição físico-química do concentrado proteico e farinha liofilizada de resíduos do pirarucu. A obtenção do concentrado proteico se deu através da modificação de uma metodologia já existente, com alterações nas etapas de desodorização e deslipidificação. E a liofilização através de um liofilizador de bancada. Nos dois métodos utilizou-se a cabeça e a carcaça do Pirarucu, separadamente, a fim de verificar se existiam diferenças significativas $(\mathrm{p} \leq 0.05) \mathrm{em}$ todas as propriedades físico-químicas avaliadas. $\mathrm{O}$ processo de liofilização e obtenção do concentrado proteico se mostraram eficientes alternativas para o uso dos resíduos do pirarucu no desenvolvimento de novos produtos, uma vez que diminuíram o teor de umidade $(80,15 \%$ para $4,57 \%)$, como concentrou os minerais $(1,60 \%$ para $7,55 \%)$ e proteínas $(5,46 \%$ para $83,05 \%)$ e reduziu o teor lipídico (20,97\% para 6,87\%).
\end{abstract}

Palavras-chave: desidratação, cabeça, carcaça.

The pirarucu (Arapaima gigas) is considered one of the largest freshwater fish in the world. However, its processing generates large amounts of waste that can add value to the development of new products, generate income for the local population and also the possibility of spreading its consumption. Among the existing methods of dehydration, freeze-drying stands out for promoting greater preservation of the sensory and nutritional characteristics of foods. Protein concentrates from fish are products obtained by dehydration that have a high protein content. Its main characteristics are its high biological value, low cost and easy conservation. The objective of this work was to evaluate the physicochemical composition of protein concentrate and freeze-dried flour from pirarucu residues. The protein concentrate was obtained by modifying an existing methodology, with changes in the deodorization and delipidification steps. And freeze-drying using a benchtop freeze-dryer. In both methods, the head and carcass of Pirarucu were used, separately, in order to verify if there were significant differences $(p \leq 0.05)$ in all physicochemical properties evaluated. The freeze-drying process and obtaining the protein concentrate proved to be efficient alternatives for the use of pirarucu residues in the development of new products, as they reduced the moisture content $(80.15 \%$ to $4.57 \%)$, as was the case with the minerals. (1.60\% to $7.55 \%)$ and proteins $(5.46 \%$ to $83.05 \%)$ and reduced the lipid content $(20.97 \%$ to $6.87 \%)$.

Keywords: dehydration, head, carcass. 


\section{INTRODUÇÃO}

O aproveitamento dos resíduos do beneficiamento do pescado além de reduzir problemas como custo e produção, contribui diretamente para a preservação ambiental. Porém o alto valor nutricional desses resíduos se destaca, pois constitui cerca da metade do volume da matéria-prima, além de ser uma fonte de nutrientes de baixo custo e ser uma excelente alternativa na elaboração de novos produtos alimentícios [1].

Os concentrados proteicos provenientes de pescado são produtos obtidos por desidratação, que possuem alto conteúdo de proteínas, apresentam em sua maioria sabor e aroma de pescado. Suas características primordiais são o alto valor biológico, baixo custo e fácil conservação. Muitas pesquisas vêm sendo desenvolvidas sobre a hidrólise de proteínas de peixe, de modo a aumentar o consumo dessa fonte marinha e concentrar esse macro nutriente que possui um potencial substancial como ingredientes para o desenvolvimento de novos produtos alimentícios [2, 3].

A liofilização, também conhecida como desidratação pelo frio, é uma técnica de desidratação que se destaca pela produção de produtos secos de alto valor agregado. A técnica é conhecida pela sua capacidade de preservar a qualidade do produto, como cor, forma, aroma e valor nutricional, devido à sua baixa temperatura de processamento e o emprego do vácuo, o que reduz as reações de degradação. $O$ processo inclui duas etapas, sendo a primeira o congelamento prévio do alimento $\left(-80^{\circ} \mathrm{C}\right)$ e a segunda onde ocorre a sublimação, ou seja, passagem da água do estado líquido para o vapor [4].

O objetivo deste trabalho foi avaliar a composição físico-química do concentrado proteico e farinhas liofilizadas obtidos a partir de resíduos do pirarucu.

\section{MATERIAL E MÉTODOS}

O presente trabalho foi desenvolvido no Laboratório de Processos de Separação de Biomoléculas e Desidratação de Alimentos da Universidade Federal do Tocantins (UFT), Campus de Palmas. Para a realização dos experimentos foram utilizados a cabeça e a carcaça íntegras do peixe Pirarucu (Arapaima gigas). Os peixes foram provenientes de alguns municípios do estado, como Palmas, Miracema, Aliança e Gurupi. Os resíduos do pirarucu foram obtidos por meio de doação de empresa de processamento de peixes em Palmas, Tocantins.

A carcaça e cabeça do peixe foram armazenadas em freezers convencionais sob congelamento até serem retirados para o preparo das amostras.

\subsection{Elaboração das farinhas liofilizadas}

Para a elaboração das farinhas liofilizadas dos resíduos do pirarucu, os mesmos foram lavados e sanitizados em solução de hipoclorito de sódio (200mg. $\mathrm{kg}^{-1}$ ), lavados novamente em água corrente e pasteurizados. Em seguida, foi adicionado $10 \%$ de maltodextrina e as amostras foram homogeneizadas e armazenadas em ultra freezer modelo DW-86L338 a $-80{ }^{\circ} \mathrm{C}$ por $24 \mathrm{~h}$. A liofilização ocorreu em um liofilizador de bancada, modelo L101, a $-60^{\circ} \mathrm{C}$ por $48 \mathrm{~h}$ (estabelecido por ensaios preliminares). Em seguida, o material liofilizado foi triturado em moinho de facas (Solab), obtendo assim as farinhas liofilizadas que foram armazenadas em embalagens flexíveis de polietileno, recobertas com papel alumínio e mantidas em dessecador a temperatura ambiente.

\subsection{Elaboração do concentrado proteico}

As amostras de resíduos do pirarucu foram primeiramente lavadas em água clorada e após com de água destilada, utilizando cerca de três vezes o volume da amostra, por 5 minutos, repetindo o processo três vezes. $\mathrm{O}$ tempo de lavagem varia de acordo com a quantidade de matéria graxa da amostra, logo aplicou-se um tempo de 20 minutos de repouso para retirada da mesma. $\mathrm{O}$ excesso de água foi filtrado utilizando um escorredor, seguido de papel de filtro, ajustando o $\mathrm{pH}$ entre 6,4$6,8 \mathrm{com}$ cloreto de sódio a $1 \%$. As amostras foram adicionadas em um Becker contendo etanol resfriado $\left(5-10^{\circ} \mathrm{C}\right)$, com volume correspondente três vezes o volume da amostra, mantidas sob 
agitação por 20 minutos e centrifugadas, repetiu-se o processo duas vezes. O excesso de etanol foi eliminado por filtração, posteriormente o resíduo foi submetido à secagem em estufa de circulação de ar a $70^{\circ} \mathrm{C}$ durante 18 horas. Por fim, o resíduo seco foi triturado e tamisado para obtenção do concentrado proteico [5, 6].

\subsection{Caracterização da matéria-prima in natura, liofilizada e concentrado proteico}

Os parâmetros analisados para a composição centesimal foram cinzas, proteínas, lipídeos e umidade conforme metodologia descrita pelo Instituto Adolfo Lutz (2008) [7].

Para as análises de higroscopicidade e solubilidade das farinhas liofilizadas e concentrado proteico utilizou-se os métodos de Cai e Eastman, respectivamente [8,9]. As análises foram realizadas em triplicatas, em três repetições.

\subsection{Análise dos resultados}

Os resultados da caracterização físico-química dos resíduos, farinhas liofilizadas e concentrado proteico foram tratados estatisticamente pela análise de variância (ANOVA) seguida do teste de Tukey ao nível de $5 \%$ de significância $(\mathrm{p} \leq 0,05)$, com o auxílio do software SISVAR versão 5.6. [10].

\section{RESULTADOS E DISCUSSÃO}

A composição centesimal dos resíduos de pirarucu in natura encontrada no presente estudo (Tabela 1) apresentou resultados semelhantes a Batalha et al. (2017) [11] e Oliveira et al. (2014) [12] que obtiveram a caracterização da carcaça do pirarucu e apresentaram umidade de $68 \%$ e $79 \%$, cinzas $1,44 \%$ e $3,42 \%$ e proteínas $15,71 \%$ e $17,56 \%$, respectivamente.

Tabela 1. Teor de umidade para os três tratamentos analisados.

\begin{tabular}{cccc}
\hline \multirow{2}{*}{ Resíduos } & \multicolumn{3}{c}{ Médias de umidade (\%) } \\
\cline { 2 - 4 } & $\mathrm{IN}$ & $\mathrm{FL}$ & $\mathrm{CP}$ \\
\cline { 2 - 4 } Cabeça & $80,15^{\mathrm{aA}} \pm 1,42$ & $5,20^{\mathrm{bB}} \pm 0,56$ & $5,12^{\mathrm{bB}} \pm 0,90$ \\
Carcaça & $78,24^{\mathrm{aA}} \pm 0,78$ & $5,81^{\mathrm{bB}} \pm 0,77$ & $4,57^{\mathrm{bB}} \pm 0,28$
\end{tabular}

Médias seguidas pela mesma letra não diferem estatisticamente entre si. Linhas: letras minúsculas. Colunas: letras maiúsculas. IN: In natura; FL: Farinhas liofilizadas; CP: Concentrado proteico.

A elevada porcentagem de umidade na cabeça e carcaça in natura confirma a alta perecibilidade desses resíduos, tornando necessária a utilização de técnicas de métodos de conservação para diminuir esse teor e consequentemente aumentar a vida de prateleira do produto final, controlando as alterações físicas, químicas e principalmente as microbiológicas [13].

A secagem interfere no teor de umidade do produto devido à remoção da água livre, sendo assim muitos microrganismos não conseguem crescer [14]. O teor de umidade das farinhas liofilizadas e dos concentrados proteicos diminuíram aproximadamente $75 \%$ do teor de água inicial nos resíduos, obtendo uma umidade final de aproximadamente 5\%, não diferindo estatisticamente entre si (Tabela 1).

Infere-se que a higroscopicidade e a umidade são propriedades que estão interconectadas entre si, tendo em vista que quando os pós desidratados apresentarem menor umidade, serão mais higroscópicos, pois há uma maior capacidade de adsorção de água, ou seja, possuem mais sítios disponíveis para que as moléculas de água se liguem, consequentemente serão mais 
higroscópicos. Por outro lado, como pode ser visto na Tabela 2, quando a umidade for alta, o pó tende a ser menos higroscópico, com menor capacidade de adsorção de água.

Tabela 2. Teor de higroscopicidade para os três tratamentos analisados.

\begin{tabular}{cccc}
\hline \multirow{2}{*}{ Resíduos } & \multicolumn{3}{c}{ Médias de higroscopicidade (\%) } \\
\cline { 2 - 4 } & IN & FL & CP \\
\hline Cabeça & - & $18,35^{\mathrm{aA}} \pm 1,47$ & $26,91^{\mathrm{bB}} \pm 0,93$ \\
Carcaça & - & $17,96^{\mathrm{aA}} \pm 1,12$ & $27,22^{\mathrm{bB}} \pm 1,09$ \\
\hline
\end{tabular}

Médias seguidas pela mesma letra não diferem estatisticamente entre si. Linhas: letras minúsculas. Colunas: letras maiúsculas. IN: In natura; FL: Farinhas liofilizadas; CP: Concentrado proteico.

A higroscopicidade é uma importante propriedade a ser estudada em produtos desidratados, visto que quando se obtém altos valores ocorrer o fenômeno do aglomerado, que nada mais é que a aglomeração espontânea de alimentos devido à alta quantidade de água adsorvida, o que prejudica seu uso [12]. As farinhas liofilizadas apresentaram baixa higroscopicidade em relação aos concentrados proteicos, esse fato pode ser explicado pela adição da maltodextrina como agente encapsulante nas farinhas, pois, segundo Tonon et al. (2009) [15], esse material possui baixa higroscopicidade, confirmando a eficiência do seu uso, no sentido de reduzir a absorção de água pelos alimentos desidratados.

O teor de cinzas refere-se aos resíduos inorgânicos da queima da matéria orgânica [6], ou seja, refere-se à quantidade de minerais presentes no alimento [16]. O teor de cinzas provém da estrutura esquelética do peixe, o qual é obtido após a retirada do filé, encontrando-se com pouca quantidade de carne aderida. Algumas indústrias utilizam esta carne mecanicamente separada (CMS). Na Tabela 3, o filé do pirarucu apresenta uma quantidade de minerais inferior à dos resíduos, tanto da cabeça como da carcaça, apesar da carcaça ter apresentado um valor mais alto neste trabalho (3,38\%), se diferindo estatisticamente do conteúdo da cabeça $(1,60 \%)$ a $5 \%$ de significância pelo teste de Tukey. Após a liofilização e concentração de proteínas, o valor de cinzas aumentou (Tabela 3) e essa diferença na composição está relacionada com a retirada de umidade e concentração dos nutrientes [11].

Tabela 3. Teor de cinzas para os três tratamentos analisados.

Médias

\begin{tabular}{lccc} 
Resíduos & \multicolumn{3}{c}{ Médias de cinzas (\%) } \\
& $\mathrm{IN}$ & $\mathrm{FL}$ & $\mathrm{CP}$ \\
\cline { 2 - 4 } Cabeça & $1,60^{\mathrm{aA}} \pm 0,53$ & $5,56^{\mathrm{bA}} \pm 0,90$ & $2,27^{\mathrm{cA}} \pm 0,28$ \\
Carcaça & $3,38^{\mathrm{aB}} \pm 0,62$ & $7,44^{\mathrm{bB}} \pm 0,57$ & $2,53^{\mathrm{cA}} \pm 0,15$ \\
\hline
\end{tabular}

seguidas pela mesma letra não diferem estatisticamente entre si. Linhas: letras minúsculas. Colunas: letras maiúsculas. IN: In natura; FL: Farinhas liofilizadas; CP: Concentrado proteico.

$\mathrm{Na}$ Tabela 4, observa-se que o teor de proteínas para os resíduos liofilizados apresentou valor superior (31,57\% e 34,59\%) ao do filé. Este valor foi semelhante ao de Boscolo et al. (2012) [17] que encontraram $33 \%$ de proteína na secagem de resíduos de tilápia, ou seja, os resíduos possuem valor nutricional considerável. Segundo Pessatti (2001) [18], a concentração de proteínas após a liofilização deve ser em torno de quatro vezes o valor de proteína encontrado na matéria-prima, logo, o método de liofilização utilizado no presente estudo mostrou-se eficiente, pois o aumento foi de aproximadamente cinco a seis vezes. O teor de proteínas no resíduo do peixe foi alta (Tabela 4), caracterizando esse subproduto como excelente fonte de obtenção desse macro nutriente, demonstrando sua efetividade na elaboração de outros produtos [13].

O teor de proteínas aumentou significativamente (Tabela 4) nos concentrados proteicos, fato que foi observado por Paiva (2015) [19] que também concentrou as proteínas dos resíduos do Pirarucu, encontrando um teor de 15,63\% nos resíduos in natura e 71,30\% no concentrado proteico demonstrando a eficiência no processo de deslipidificação, desta forma concentrando os percentuais de proteínas. 
Tabela 4. Teor de proteínas para os três tratamentos analisados.

Médias

\begin{tabular}{lccc} 
Resíduos & \multicolumn{3}{c}{ Médias de proteínas (\%) } \\
& IN & FL & CP \\
\cline { 2 - 4 } Cabeça & $5,46^{\mathrm{aA}} \pm 1,11$ & $31,57^{\mathrm{bA}} \pm 3,23$ & $80,59^{\mathrm{cA}} \pm 4,00$ \\
Carcaça & $7,90^{\mathrm{aA}} \pm 0,81$ & $34,59^{\mathrm{bA}} \pm 0,93$ & $83,04^{\mathrm{cA}} \pm 3,95$
\end{tabular}

seguidas pela mesma letra não diferem estatisticamente entre si. Linhas: letras minúsculas. Colunas: letras maiúsculas. IN: In natura; FL: Farinhas liofilizadas; CP: Concentrado proteico.

O conteúdo de lipídeos no pescado sofre alterações dependendo da época do ano, da dieta do peixe, temperatura da água, salinidade, espécie, sexo e da parte do corpo a ser analisada, no pirarucu pode-se afirmar que a parte com menor conteúdo de gordura encontrado é no filé $(0,2 \%$ a $0,4 \%$ ), sendo considerado um peixe magro [20]. Porém, como pode ser visto na Tabela 5, os resíduos in natura e principalmente as farinhas liofilizadas apresentaram alta taxa de gordura.

Segundo Vidal et al. (2011) [21], a alta taxa de gordura após a secagem pode ser explicada pela relação inversa entre os teores de gordura e os teores de umidade, pois quando a umidade é reduzida o teor de lipídeos aumenta. Com isso, essa alta concentração pode levar a instabilidade do produto quando se trata de reações oxidativas, que podem por consequência, diminuir a vida útil do produto pela rancificação [22].

Com relação ao teor lipídico dos concentrados proteicos, os valores foram relativamente elevados (Tabela 5), estabelecendo dessa forma um obstáculo na obtenção do CP, uma vez que o produto deve apresentar baixa concentração de gordura, possibilitando aumento da sua estabilidade com relação a reações oxidativas [6].

Tabela 5. Teor de lipídeos para os três tratamentos analisados.

\begin{tabular}{cccc}
\hline Resíduos & \multicolumn{3}{c}{ Médias de lipídeos (\%) } \\
& IN & FL & CP \\
\cline { 2 - 4 } Cabeça & $9,04^{\mathrm{aA}} \pm 0,23$ & $15,29^{\mathrm{bA}} \pm 1,41$ & $6,87^{\mathrm{cA}} \pm 0,67$ \\
Carcaça & $10,74^{\mathrm{aA}} \pm 0,34$ & $20,97^{\mathrm{bB}} \pm 0,27$ & $7,02^{\mathrm{cA}} \pm 0,76$ \\
\hline
\end{tabular}

Médias seguidas pela mesma letra não diferem estatisticamente entre si. Linhas: letras minúsculas. Colunas: letras maiúsculas. IN: In natura; FL: Farinhas liofilizadas; CP: Concentrado proteico.

As farinhas liofilizadas apresentaram solubilidade da cabeça e carcaça de 69,64\% e 58,38\%, respectivamente.

A solubilidade dos concentrados proteicos foi relativamente baixa quando comparada com a solubilidade das farinhas liofilizadas (Tabela 6).

Tabela 6. Teor de solubilidade para os tratamentos analisados

\begin{tabular}{cccc}
\hline Resíduos & \multicolumn{3}{c}{ Médias de solubilidade (\%) } \\
Cabeça & - & FL & CP \\
\cline { 2 - 4 } & - & $69,64^{\mathrm{aA}} \pm 0,41$ & $47,646^{\mathrm{bA}} \pm 0,87$ \\
Carcaça & - & $58,38^{\mathrm{aB}} \pm 0,34$ & $47,316^{\mathrm{bA}} \pm 0,96$
\end{tabular}

Médias seguidas pela mesma letra não diferem estatisticamente entre si. Linhas: letras minúsculas. Colunas: letras maiúsculas. IN: In natura; FL: Farinhas liofilizadas; CP: Concentrado proteico.

O uso de solventes para o processo de deslipidificação envolve o aquecimento de uma mistura com álcoois, como etanol ou álcool isopropílico e agitação constante durante um período de tempo, diminuindo a degradação bacteriana e eliminando o odor característico de peixe [22]. Porém, a solubilidade é afetada, devido ao grau mais baixo de hidrólise em comparação com as proteínas que não foram desengorduradas [23]. 


\section{CONCLUSÃO}

O processo de liofilização e obtenção do concentrado proteico mostraram-se eficientes alternativas para o uso dos resíduos do pirarucu no desenvolvimento de novos produtos. Como forma de agregação de valor, diminuiu consideravelmente o teor de umidade, sendo uma excelente estratégia para o aumento da vida de prateleira, como também a concentração de mineirais e proteínas e deslipidificação das amostras. Desta forma, a utilização da cabeça e carcaça do Pirarucu das mais variadas formas pode aumentar o consumo de proteínas pela população e consequentemente diminuir o impacto ambiental causado pelo descarte dos mesmos.

\section{REFERÊNCIAS BIBLIOGRÁFICAS}

1. Silva DCF, Gonçalves AA. Perfil de consumo de pescado dos usuários do restaurante universitário da UFERSA. Mossoró (RN): Rev Caatinga. 2020;25(3):118-24.

2. Galla NR, Pamidighantamm PR, Akula S, Karakala B. Functional properties and in vitro antioxidant activity of roe protein hydrolysates of Channa striatus and Labeo horita. Food Chem. 2012 Dec;135(3):1479-84. doi: 10.1016/j.foodchem.2012.05.098

3. Nasri RI, Younes M, Jridi M, Trigui A, Boutagef N, Nedjar-Arroume, et al. ACE-inhibitory and antioxidative activities of Goby (Zosterissessor ophiocephalus) (FPH): effect on meat lipid oxidation. Food Res Int. 2013 Nov;54(1):552-61. doi: 10.1016/j.foodres.2013.07.001

4. Oikonomopoulou VP, Krokida MK. Structural properties of dried potatoes, mushrooms, and strawberries as a function of freeze-drying pressure. Dry Technol. 2013 Jan;30(4)351-61. doi: 10.1080/07373937.2011.639475

5. Quaglia, GB, Orban E. Enzymic solubilisation of proteins of sardine (Sardina pilchardus) by commercial proteases. J Sci Food Agric. 1987;38(3):263-9. doi: 10.1002/jsfa.2740380310

6. Guida LM, Barbosa MC, Feitosa AC, Leite JF, Zuniga ADG. Caracterização do concentrado proteico de peixe obtido a partir da cabeça do pirarucu (Arapaima gigas). In: Neto BRS, editor. A produção do conhecimento nas ciências da saúde 2 [recurso eletrônico]. Ponta Grossa (PR): Atena Editora; 2019. p. 150-155.

7. Instituto Adolfo Lutz (IAL). Métodos físico-químicos para análise de alimentos. 4. ed. São Paulo (SP): IAL; 2008.

8. Cai Y, Corke H. Production and properties of spray-dried amaranthus betacyanin pigments. J Food Sci. 2000 Jul;65(7):1248-52. doi: 10.1111/j.1365-2621.2000.tb10273.x

9. Eastman JE, Moore CO, inventors; Staley Manufacturing AE, assignee. Cold water soluble granular starch for gelled food composition. US Patent 4,465,702. 1984 Aug 14.

10. Ferreira DF. Sisvar: a computer statistical analysis system. Cienc Agrotec. 2011;35(6):1039-42. doi: 10.1590/S1413-70542011000600001

11. Batalha OS, Alfaia SS, Cruz FGG, Jesus RS, Rufino JPF, Costa VR. Digestibility and physico-chemical characteristics of acid silage meal made of pirarucu waste in diets for commercial laying hens. Acta Sci. Anim Sci. 2017 Jul-Sep;39(3):251-7. doi: 10.4025/actascianimsci.v39i3.35112

12. Oliveira PR, Jesus RS, Batista GM, Lessi E. Avaliação sensorial, físico-química e microbiológica do pirarucu (Arapaima gigas, Schinz 1822) durante estocagem em gelo. Braz. J Food Technol. 2014 Mar;17(1):67-74. doi: 10.1590/bjft.2014.010

13. Reboucas MC, Rodrigues MCP, Castro RJS, Vieira JMM. Caracterização do concentrado protéico de peixe obtido a partir dos resíduos da filetagem de tilápia do Nilo. Semina: Ciênc. Agrár. 2012 Abr;33(2):697-704. doi: 10.5433/1679-0359.2012v33n2p697

14. Jay JM, Loessner MJ, Golden DA. Modern food microbiology. 7. ed. New York (US): Springer Science; 2005.

15. Tonon RV, Brabet $\mathrm{C}$, Hubinger, MD. Influência da temperatura do ar de secagem e da concentração de agente carreador sobre as propriedades físico-químicas do suco de açaí em pó. Ciênc Tecnol Aliment. 2009 Jun;29(2):444-50. doi: 10.1590/s0101-20612009000200034

16. Gadelha AJF, Rocha CO, Vieira FF, Ribeiro GN. Parâmetros de qualidade físico-químicos de polpas congeladas de abacaxi, acerola, cajá e caju. Rev Caatinga. 2009 Mar;22(1):115-8. Disponível em: https://periodicos.ufersa.edu.br/index.php/caatinga/article/view/1012

17. Boscolo WR, Feiden A, Signor AA, Klein S, Bittencourt F, Corrêia AF. Resíduos da indústria de filetagem de tilápia do nilo (Oreochromis niloticus) na forma de farinhas e silagem para a alimentação de lambari (Astianax bimaculatus). Ciênc Anim Bras. 2017;10(2):189-95. doi: 10.7213/academica.7697

18. Pessatti ML. Aproveitamento dos subprodutos do pescado. Itajaí (SC): MAPA/UNIVALI; 2001. 
19. Paiva FC, Alecrim MM, Teixeira MFS, Kirsch LS, Jesus RS. Produção de hidrolisado proteico de pirarucu utilizando-se protease de Aspergillus flavo-furcatis e pancreatina. Pesq Agropec Bras. 2015 Mar;45(1):89-96. doi: 10.1590/1983-40632015v4529838

20. Ogawa M. Alterações da carne de pescado por processamento e estocagem. In: Ogawa M, Maia E, organizadores. Manual de pesca: Ciência e tecnologia do pescado. vol. 1. São Paulo: Livraria Varela; 1999. p. 221-49.

21. Vidal JMA, Rodrigues MCP, Zapata JFF, Vieira JMM. Concentrado protéico de resíduos da filetagem de tilápia-do-nilo (Oreochromis niloticus): caracterização físico-química e aceitação sensorial. Rev Cienc Agron. 2011 Mar;42(1):92-9. doi: 10.1590/S1806-66902011000100012

22. Kristinsson HG, Rasco BA. Fish protein hydrolysates: Production, biochemical, and functional properties. Crit Rev Food Sci Nutr. 2000 Jan;40(1):43-81. doi: 10.1080/10408690091189266

23. Klompong VS, Benjakul D, Kantachote FS. Antioxidative activity and functional properties of protein hydrolysate of yellow stripe trevally (Selaroides leptolepis) as influenced by the degree of hydrolysis and enzyme type. Food Chem. 2007 Out;102(4):1317-27. doi: 10.1016/j.foodchem.2006.07.016 